\title{
Taurine supplementation to anti-seizure drugs as the promising approach to treat pharmacoresistant epilepsy: A pre-clinical study
}

\author{
Sandeep Kumar, Rajesh Kumar Goel* \\ Department of Pharmaceutical Sciences \& Drug Research, Punjabi University, Patiala, India
}

\section{A R T I C L E I N F O}

\section{Article history:}

Received 26 February 2017

Accepted 20 July 2017

Available online 25 July 2017

\section{Keywords:}

Epilepsy

Kindling

Lamotrigine

Pharmacoresistant

Supplementation

Taurine

\begin{abstract}
A B S T R A C T
Background: Pharmacoresistance leads to severe, irreversible disabilities and premature death in $~ 30 \%$ cases of epilepsy despite adequate and appropriate treatment with available anti-seizure drugs (ASDs) without any underlying cause. In light of the large body of evidence which suggests the anti-seizure action of taurine in experimental animals and its wide safety margins in human, supplementation of this inhibitory amino-sulfonic acid to available ASDs seems promising to treat pharmacoresistant epilepsy. Methods: We examined the anti-seizure effect of lamotrigine $(15 \mathrm{mg} / \mathrm{kg})$, levetiracetam $(40 \mathrm{mg} / \mathrm{kg})$, carbamazepine $(40 \mathrm{mg} / \mathrm{kg})$, phenytoin $(35 \mathrm{mg} / \mathrm{kg}) \&$ taurine $(50,100 \& 200 \mathrm{mg} / \mathrm{kg})$ in lamotrigine pretreated pentylenetetrazole-kindled mice (LPK) which mimic core features of pharmacoresistant epilepsy, either alone ASDs or in combinations whereby three different doses of taurine were supplemented with tested ASDs.

Results: Both, the ASDs and the taurine were failed to suppress generalized tonic-clonic seizures in LPK mice. However, taurine supplementation clearly restored the anti-seizure effect of tested ASDs. Further neurochemical studies revealed that higher levels of taurine in the hippocampus and cerebral cortex restored the imbalance between major excitatory neurotransmitters glutamate \& its inhibitory counterpart GABA.

Conclusions: These findings emphasize that supplementation of taurine with ASDs may be useful to treat pharmacoresistant epilepsy. Thus, further clinical validation is encouraged.

(C) 2017 Published by Elsevier, a division of RELX India, Pvt. Ltd on behalf of Indian Epilepsy Society.
\end{abstract}

\section{Introduction}

Persistent seizures is a characteristic feature of pharmacoresistant epilepsy as clear from $\sim 30 \%$ of 65 million total worldwide cases of epilepsy, despite adequate and appropriate treatment with available ASDs. $^{1-3}$ It leads to developmental delay, severe irreversible disabilities and premature deaths, suggesting that seizure control is important. ${ }^{4}$

In order to limit severity and frequency of persistent disabling seizures, ASD combinations possessing multiple mechanisms of actions can be considered ${ }^{1}$ however; serious adverse effects and drug interactions often limit their usage. ${ }^{5}$ Moreover, chronic polytherapy further aggravates epilepsy associated comorbidities such as depression and memory impairment. ${ }^{6}$ On the other side, available non-pharmacological alternatives such as neurosurgery, central \& peripheral neurostimulation are clinically underutilized, either due to ineffectiveness or inappropriateness. ${ }^{7-10}$

\footnotetext{
* Corresponding author.

E-mail address: goelrkpup@gmail.com (R.K. Goel).
}

Thus, epilepsy field suffers from pharmacoresistance despite intensive epilepsy research over the years and clinical availability of more than ten leading ASDs. Thus, much interest is in the development of safe and effective treatment approaches, with an emphasis to restore drug response in pharmacoresistant epilepsy.

The precise pathological mechanisms underlying pharmacoresistance in epilepsy stay elusive. ${ }^{3}$ However, disturbance in regulatory roles of excitatory and inhibitory amino acids are thought to lead neuronal hyperexcitability in epilepsy. ${ }^{11-13}$ In this context, uses of neuroactive amino acids have been recently drawn in for treatments of pharmacoresistant epilepsy. ${ }^{14,15}$ Another believed disturbance is the failure of neuronal regulation by taurine, an inhibitory amino sulfonic acid. ${ }^{13}$

In parallel to this, supplementation of taurine to available ASDs seems an promising approach to treat pharmacoresistant epilepsy, considering favourable effects of this inhibitory amino sulfonic acid such as neuroprotection from glutamate induced excitetoxicity, ${ }^{16,17}$ direct agonistic action at $\mathrm{GABA}_{\mathrm{A}}$ receptor complex, ${ }^{18,19}$ enhancement of GAD activity and GAD-positive neurons ${ }^{20,21}$ as well proven anti-convulsant effect ${ }^{22,23}$ with wide margin of clinical safety $^{24}$ made the choice convincing. 
The Epilepsy Therapy Screening Program of National Institute of Neurological Disorder \& Stroke (NINDS) offer a battery of wellestablished rodent seizure models to screen promising molecules. Among these, lamotrigine resistant seizures in Swiss albino mice mimics core features of pharmacoresistant epilepsy. ${ }^{25-28}$ Therefore, this study was aimed to evaluate taurine supplementation to known ASDs, as promising approach to treat pharmacoresistance on LPK mice model of pharmacoresistant epilepsy.

\section{Materials and methods}

\subsection{Animals}

Experiments were performed on total forty-two adult male Swiss albino mice (obtained from a breeder, Lala Lajpat Rai University of Veterinary and Animal Science, Hisar, Haryana, India). Mice were kept in plastic cages (6 mice/cage) in the animal house condition, at controlled room temperature $\left(22 \pm 3^{\circ} \mathrm{C}\right)$, humidity $(50 \pm 5 \%)$ and light-dark cycle ( $12 \mathrm{~h}$ light: $12 \mathrm{~h}$ dark, lights on at 8:00 am) with free access to food (standard pellets for rodents) and water (ad libitum), except during experimental schedules. The experimental protocol was duly approved by the Institutional Animal Ethics Committee (protocol approval no. 107/99/CPCSEA/ 2014-08). Experiments were carried out as per guidelines laid down by the Committee for the Purpose of Control and Supervision of Experiments on Animals (CPCSEA), Ministry of Environment and Forest, Government of India. The cages were cleaned regularly. Mice were acclimatized to the laboratory for a week, before these experiments. For pentylenetetrazole kindling model, $\mathrm{n}=10$ mice were used, termed as PK mice. For lamotrigine pre-treated pentylenetetrazole kindling model, $\mathrm{n}=32$ mice were used, termed as LPK mice. For both the models, mice were of twelve-week-age and individual body weight $25-28 \mathrm{~g}$ at the time of seizure induction.

\subsection{Pentylenetetrazole kindling model}

The pentylenetetrazole kindling is a well-established rodent seizure model that mimics core features of pharmacoresponsive epilepsy and widely employed in the screening of potential molecules. ${ }^{25}$ It involves a progressive increase in seizure susceptibility of rodents due to repeated pentylenetetrazole treatments. ${ }^{29-}$

${ }^{31}$ For this, $\mathrm{n}=10$ mice were treated with a sub-convulsive dose of pentylenetetrazole $(40 \mathrm{mg} / \mathrm{kg})$ on alternate days. Pentylenetetrazole (Sigma-Aldrich, USA) was dissolved in normal saline and administered via i.p route at every $48 \pm 2 \mathrm{~h}$ intervals. After every injection, mice were placed individually in transparent plexiglass cages $(20 \times 20 \times 30 \mathrm{~cm})$ and convulsive seizures were recorded visually for a time period of 30 mins, as per modified Racine's scale which is mentioned as: Stage 0: no response; Stage 1: hyperactivity, restlessness and vibrissae twitching; Stage 2: head nodding, head clonus and myoclonic jerks; Stage 3: unilateral or bilateral limb clonus; Stage 4: forelimb clonic seizures; Stage 5: generalized tonic-clonic seizures with falling; Stage 6: hind limb extension. Pentylenetetrazole treatments continue for each mouse until it has achieved the criterion of 3 consecutive stage 5 seizures, whereby it is considered in a "stable kindled state". ${ }^{29-31}$ Mortality was observed in 2 out of 10 mice.

\subsection{Lamotrigine pre-treated pentylenetetrazole kindling model}

The lamotrigine pre-treated pentylenetetrazole kindled mice mimic core features of pharmacoresistant epilepsy and described in detail. ${ }^{25,26}$ Briefly, this model has modified the traditional kindling protocol with the addition of lamotrigine pre-treatments during kindling acquisition phases, which does not inhibit kindling acquisition, but leads to the subsequent development of pharmacoresistant seizures in kindled animals. For this study, $\mathrm{n}=32$ mice received lamotrigine pre-treatments $(5 \mathrm{mg} / \mathrm{kg}$ suspended in $0.5 \%$ methylcellulose, i.p) at $45 \mathrm{~min}$ before every pentylenetetrazole

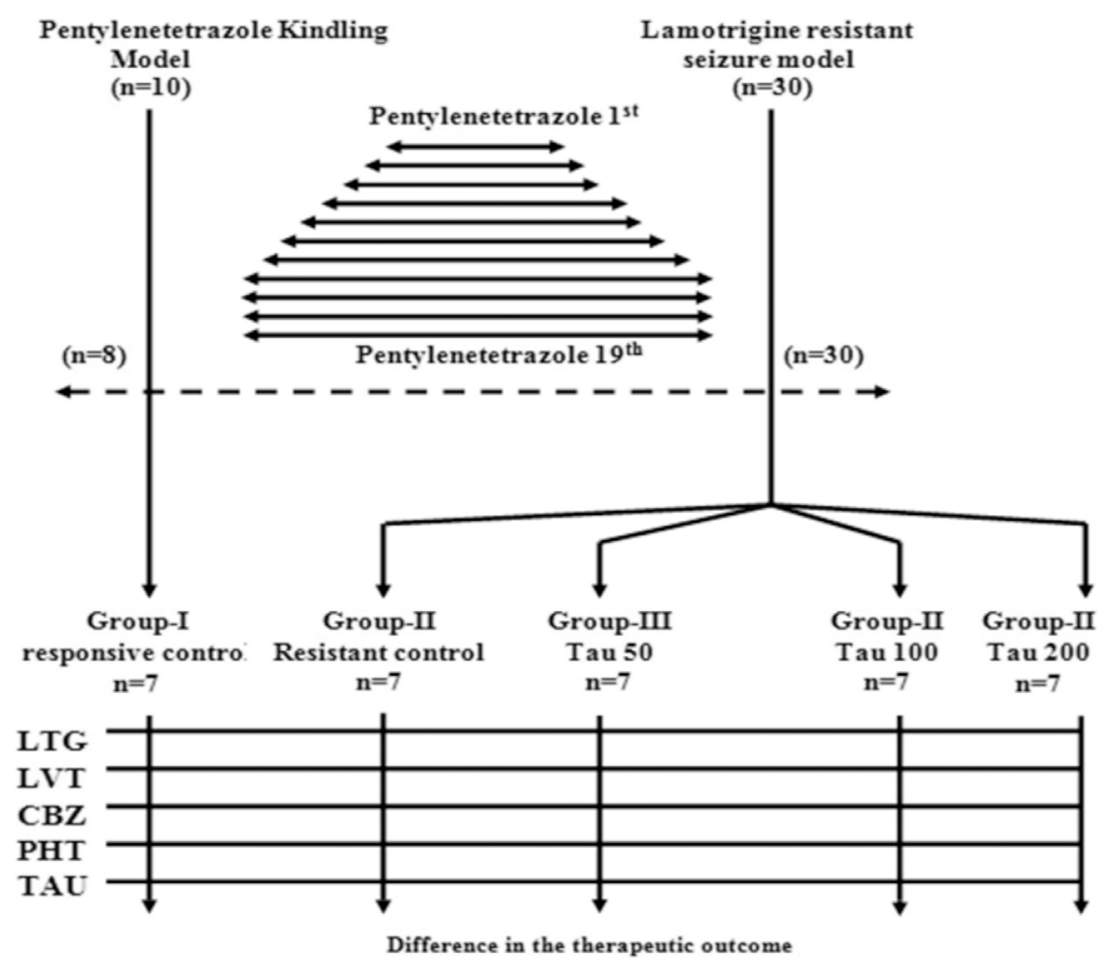

Fig. 1. Schematic illustration of the study design. 
treatment $(40 \mathrm{mg} / \mathrm{kg}$ at $48 \pm 2 \mathrm{~h}$ intervals) till stable kindled state. ${ }^{26}$ Mortality in this kindling protocol was low (2/32).

\subsection{Drug testing}

Starting $48 \mathrm{~h}$ after the kindling protocols, standard drugs were tested with $\mathrm{v} / \mathrm{s}$ without taurine supplementations: 7 PK mice and 30 LPK mice were used for these experiments (Fig. 1). For this, PK mice were assigned as (i) pharmacoresponsive control group-I in which $n=7$ PK mice received standard anti-seizure drug treatment without taurine supplementation. Another side, the LPK mice were randomly assigned into 4 groups (ii) pharmacoresistant control group-II in which $n=7$ LPK mice received standard drug treatment without taurine supplementation (iii) Group-III in which $n=7$ LPK mice received $50 \mathrm{mg} / \mathrm{kg}$ i.p dose of taurine $1 \mathrm{~h}$ before standard drug treatment (iv) Group-IV in which $\mathrm{n}=7$ LPK mice received $100 \mathrm{mg} /$ $\mathrm{kg}$ i.p dose of taurine $1 \mathrm{~h}$ before standard drug treatment $(\mathrm{v})$ Group-V in which $\mathrm{n}=7$ LPK mice received $200 \mathrm{mg} / \mathrm{kg}$ i.p dose of taurine $1 \mathrm{~h}$ before standard drug treatment.

ASDs were tested at well-established therapeutic efficacious doses, in ascending order of their elimination half-life's i.e. $15 \mathrm{mg} /$ $\mathrm{kg}$ lamotrigine suspended in $0.5 \%$ methylcellulose, i.p (obtained from Cadila Healthcare, India), $40 \mathrm{mg} / \mathrm{kg}$ levetiracetam in normal saline, i.p, $\mathrm{t}^{1 / 2} \sim 1.5 \mathrm{~h}$ (Torrent, India), $40 \mathrm{mg} / \mathrm{kg}$ carbamazepine in $0.5 \%$ methyl cellulose, i.p, $\mathrm{t}^{1 / 2} \sim 2 \mathrm{~h}$ (Sun, India) and $35 \mathrm{mg} / \mathrm{kg}$ phenytoin in normal saline, $\mathrm{t}^{1 / 2} \sim 12 \mathrm{~h}$ (Troikaa, India) with adequate washout period of $48 \mathrm{~h}$ for each drug except $96 \mathrm{~h}$ for phenytoin. ${ }^{32,33,34}$ In all five groups, mice were challenged with pentylenetetrazole $(40 \mathrm{mg} / \mathrm{Kg}$, i.p) with the time gap of $45 \mathrm{mins}$ after standard drug treatment. The severity of convulsive seizures was scored according to modified Racine's scale. Additionally, antiseizure effect of taurine per se was studied in all five groups, at an $\mathrm{i}$. $\mathrm{p}$ dose of $200 \mathrm{mg} / \mathrm{kg}$.

\subsection{Neurochemical analysis}

The levels of taurine, glutamate \& GABA in cerebral cortex and hippocampus areas of mice brain were estimated by the HPLC-ECD method. ${ }^{35}$ After therapeutic evaluation, the animals were decapitated. Cerebral cortex and hippocampus were dissected, ${ }^{36}$ weighed and homogenized in freshly prepared ice-cold $10 \% \mathrm{w} / \mathrm{v}$ perchloric acid followed by centrifugation at $14,000 \mathrm{~g}$ for $30 \mathrm{~min}$ at $4{ }^{\circ} \mathrm{C}$ (REMI C-24BL, cooling centrifuge, REMI, India) to get clear supernatant for rapid analysis of taurine, glutamate \& GABA. ${ }^{35,37}$

Briefly, chromatographic separations were made using a Waters HPLC system (Milford, USA) consisted of 515 binary pumps (Waters, USA) and Rheodyne manual injector $(20 \mu \mathrm{l})$ with Hamilton syringe. Separations were achieved on reverse phase column $(250 \mathrm{~mm} \times 4.6 \mathrm{~mm} \times 5 \mu \mathrm{m}$; Sun fire, USA $)$ at $35 \pm 1^{\circ} \mathrm{C}$ temperature followed by electrochemical detection (2465, Waters, USA). The acquired data was processed as an area under the curve (AUC) using Empower Pro-III Operating System (Waters, Milford, USA).

The mobile phase consisted of $100 \mathrm{mM}$ sodium dihydrogen phosphate: methanol (60:40) and $36 \mathrm{mg}$ EDTA per liter. The solution was adjusted to $\mathrm{pH} 7.8$ with o-phosphoric acid and filtered through a $0.45 \mu \mathrm{m}$ membrane (Millipore, USA) and degaussed (Transonic T 570/H, Elma, Germany). The flow rate was set at $1.2 \mathrm{ml} / \mathrm{min}$. Standard GABA was obtained from central drug house (New Delhi, India), glutamate from S.D Fine Chem. Ltd. (India) and taurine from Hi-media laboratory, Mumbai (India).

\subsection{Statistics}

Statistical analysis was performed using Graph Pad Prism software version 7 (Graph-Pad Software Inc., San Diego, CA, USA). The nonparametric one-way ANOVA followed by Student Newman Keuls multiple comparison post hoc tests were used for statistical evaluation of data generated from drug testing experiments \& neurochemical analysis. The data is expressed as mean \pm standard error mean. Differences were considered significant at $\mathrm{P}<0.05$.

\section{Results}

\subsection{Induction of kindling}

No significant differences were observed in the mean seizure severity score of PK mice as compared with that of LPK mice, at any point of time throughout the kindling (independent Student's $t$ -

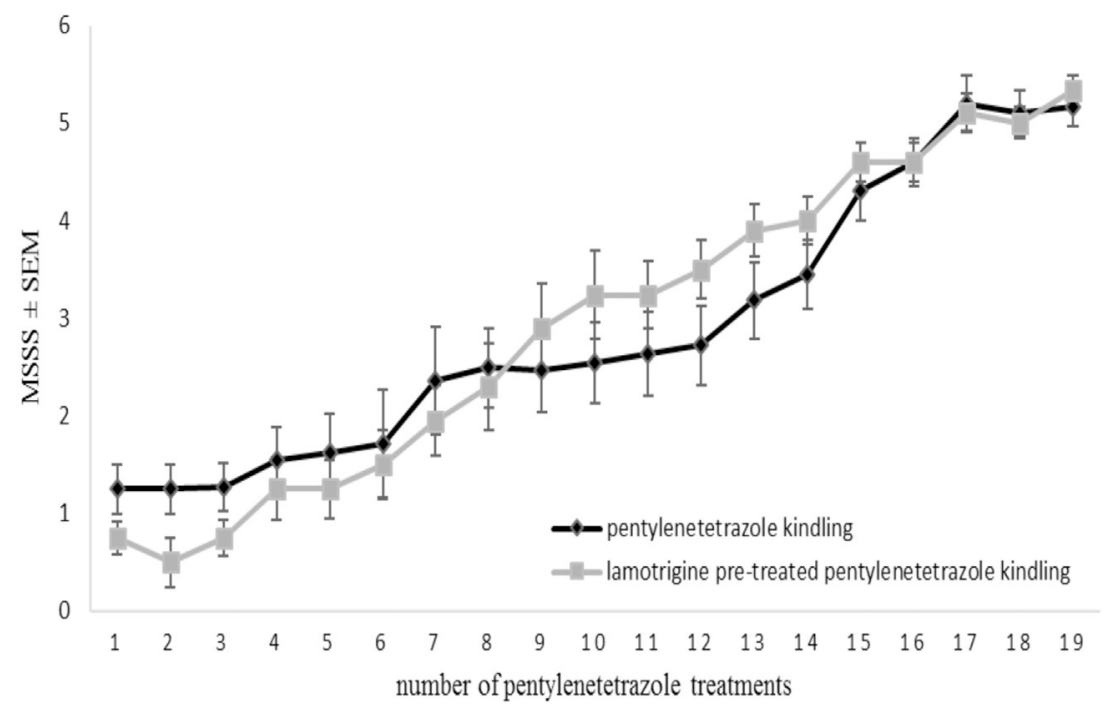

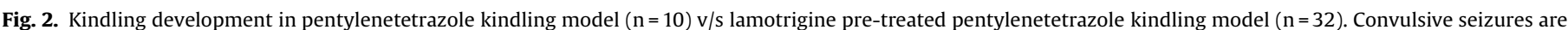

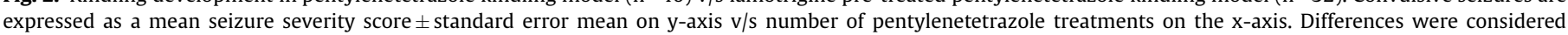
significant at $\mathrm{P}<0.05$ (Independent Student's $t$-test). 
test; $\mathrm{P}>0.05)$. Mice were kindled within $17 \pm 2$ pentylenetetrazole treatments in both the models (Fig. 2).

\subsection{Development of resistance to anti-seizure drugs}

An acute lamotrigine treatment $(15 \mathrm{mg} / \mathrm{Kg}$, i.p) completely blocked the generalized convulsive seizures on PK mice i.e. group-I (mean seizure severity score $1.2, n=6$; Fig. 3 ). In contrast, similar treatment by lamotrigine was found to be ineffective on LPK mice i.e. group-II (mean seizure severity score $4.1, \mathrm{n}=6$ ). This significant difference in the mean seizure severity scores $(1.2 \mathrm{v} / \mathrm{s} 4.2, \mathrm{P}<0.05$; Independent Student's $t$-test) represents the lamotrigine resistance in group-II.

Furthermore, differences in mean seizure severity scores of group-I v/s II after: levetiracetam $(40 \mathrm{mg} / \mathrm{kg})$ was $1.0 \mathrm{v} / \mathrm{s} 3.5$ $(\mathrm{P}<0.05$; Independent Student's $t$-test), carbamazepine $(40 \mathrm{mg} /$ $\mathrm{kg}) 1.2 \mathrm{v} / \mathrm{s} 4.0(\mathrm{P}<0.05$; Independent Student's $t$-test $)$, phenytoin $(35 \mathrm{mg} / \mathrm{kg}) 1.3 \mathrm{v} / \mathrm{s} 3.7(\mathrm{P}<0.05$; Independent Student's $t$-test $) \&$ taurine $(200 \mathrm{mg} / \mathrm{kg})$ was $1.9 \mathrm{v} / \mathrm{s} 4.1 \quad(\mathrm{P}<0.05 ;$ Independent Student's $t$-test). These results represent that in group-II resistance was not limited to lamotrigine but extended to levetiracetam, carbamazepine, phenytoin \& taurine as well.

\subsection{Restoration of anti-seizure effect by taurine}

A significant difference in the anti-convulsant effect of lamotrigine $\left(\mathrm{F}_{(4,27)}=10.9, \mathrm{P}<0.0001\right)$, levetiracetam $\left(\mathrm{F}_{(4,27)}=16.2\right.$, $\mathrm{P}<0.0001)$, carbamazepine $\left(\mathrm{F}_{(4,27)}=7.5, \mathrm{P}<0.0001\right) \&$ phenytoin $\left(F_{(4,27)}=16.0, P<0.0001\right)$ was observed between group I to $\mathrm{V}$

The anti-seizure effect of lamotrigine, levetiracetam, carbamazepine \& phenytoin was significantly $(\mathrm{P}<0.05)$ restored in taurine treated animals (group-IV \& V) as compared to control pharmacoresistant animals (group-II). The difference in the mean seizure severity score of group-II v/s III, IV \& V after lamotrigine treatment was $4.1 \mathrm{v} / \mathrm{s} 3.8,3.0,2.1(\mathrm{P}<0.05$ except II $\mathrm{v} / \mathrm{s}$ III $)$, levetiracetam treatment was $3.2 \mathrm{v} / \mathrm{s} 2.0,1.4 \& 1.0(\mathrm{P}<0.05)$, carbamazepine treatment was $4.1 \mathrm{v} / \mathrm{s} \quad 3.7,2.8 \& 2.2(\mathrm{P}<0.05$ except II v/s III) and phenytoin treatment was $4.1 \mathrm{v} / \mathrm{s} 3.6,2.4 \& 2.1$, $(\mathrm{P}<0.05$ except II v/s III).

\subsection{Neurochemical changes}

In taurine treated animals, taurine levels were found to be significantly enhanced in the cerebral cortex $\left(F_{(5,30)}=26.6\right.$; $\mathrm{P}<0.001)$ and hippocampus $\left(\mathrm{F}_{(5,30)}=77.1 ; \mathrm{P}<0.001\right)$ in comparison to control animals that received drug treatment only (group-IV \& V v/s I \& II, in Fig. 4a).

The control pharmacoresistant animals (group-II) showed significantly reduced GABA levels in comparison to control pharmacoresponsive animals (group-I; Fig. 4b). However, taurine treatment in pharmacoresistant animals (group-V) significantly up-regulated the GABA levels in cerebral cortex $\left(F_{(5,30)}=9.90\right.$; $\mathrm{P}<0.001)$ \& hippocampus $\left(\mathrm{F}_{(5,30)}=10.9 ; \mathrm{P}<0.001\right)$.

The control pharmacoresistant animals (group-II) showed significantly elevated glutamate levels in comparison to control pharmacoresponsive animals (group-I Fig. 4c). However, taurine treatments in pharmacoresistant animals (group-V) significantly down-regulated the glutamate levels in cerebral cortex ( $\mathrm{F}$ $(5,30)=25.3 ; \mathrm{P}<0.001) \&$ hippocampus $\left(\mathrm{F}_{(5,30)}=77.1 ; \mathrm{P}<0.001\right)$.

\section{Discussion}

Disturbance in the regulatory roles of neuroexcitatory and inhibitory amino acids are thought to lead neuronal hyperexcitability in epilepsy. ${ }^{11-13}$ In this context, uses of neuroactive amino acids have been recently drawn in for treatments of pharmacoresistant epilepsy. ${ }^{14,15}$ Parallel to this, another disturbance that is believed to occur is the failure of neuronal regulation by taurine, ${ }^{13}$ an inhibitory amino sulfonic acid.

A large body of evidence support to the anti-seizure effect of taurine $^{22,23,38,39}$ is based on the agonistic action of taurine on $\mathrm{GABA}_{\mathrm{A}}$ receptors ${ }^{18,19}$ as well as its ability to enhance GAD (glutamic acid decarboxylase) number \& activity in the brain $^{20,21}$ that potentiates GABAergic neurotransmission, in addition to its ability to protect neurons from glutamate induced excite-toxicity. ${ }^{17}$

However, in this first of its kind study several novel findings have been made on (i) anti-seizure effect of taurine on lamotrigine pre-treated pentylenetetrazole-kindled mice that mimic core features of pharmacoresistant epilepsy rather than its previously

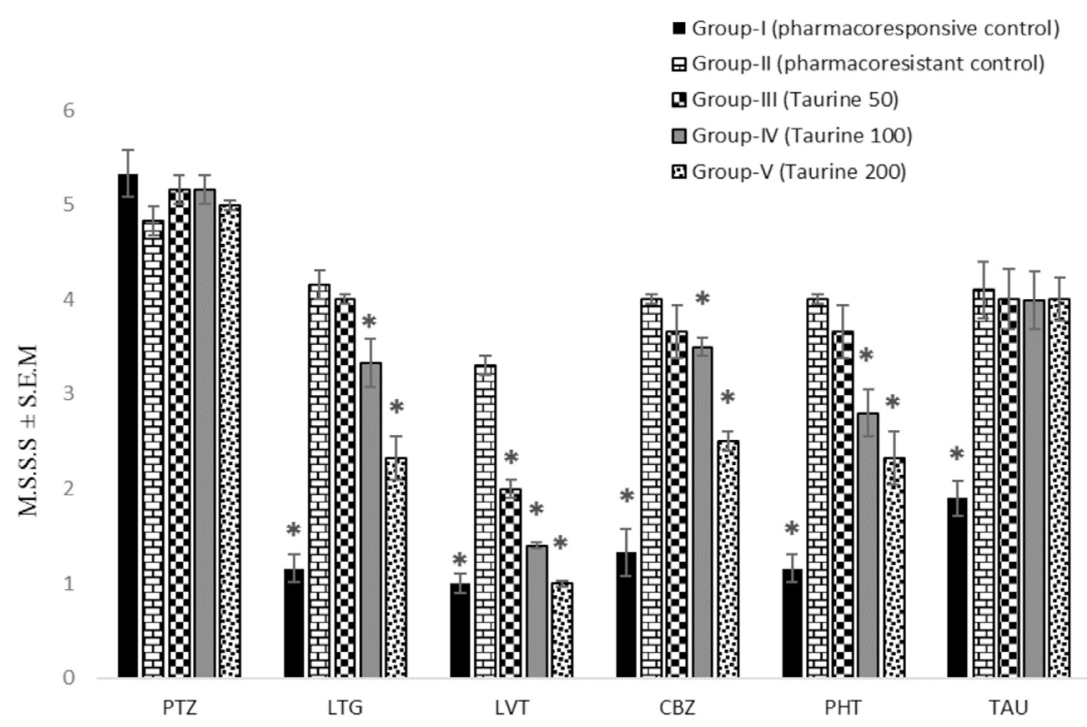

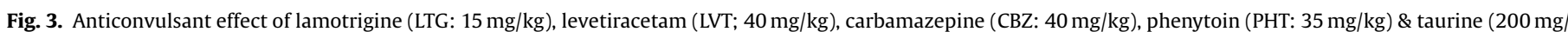

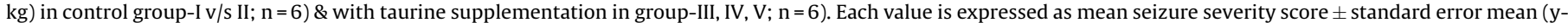

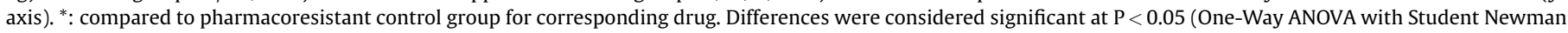
Keuls multiple comparison post hoc). 

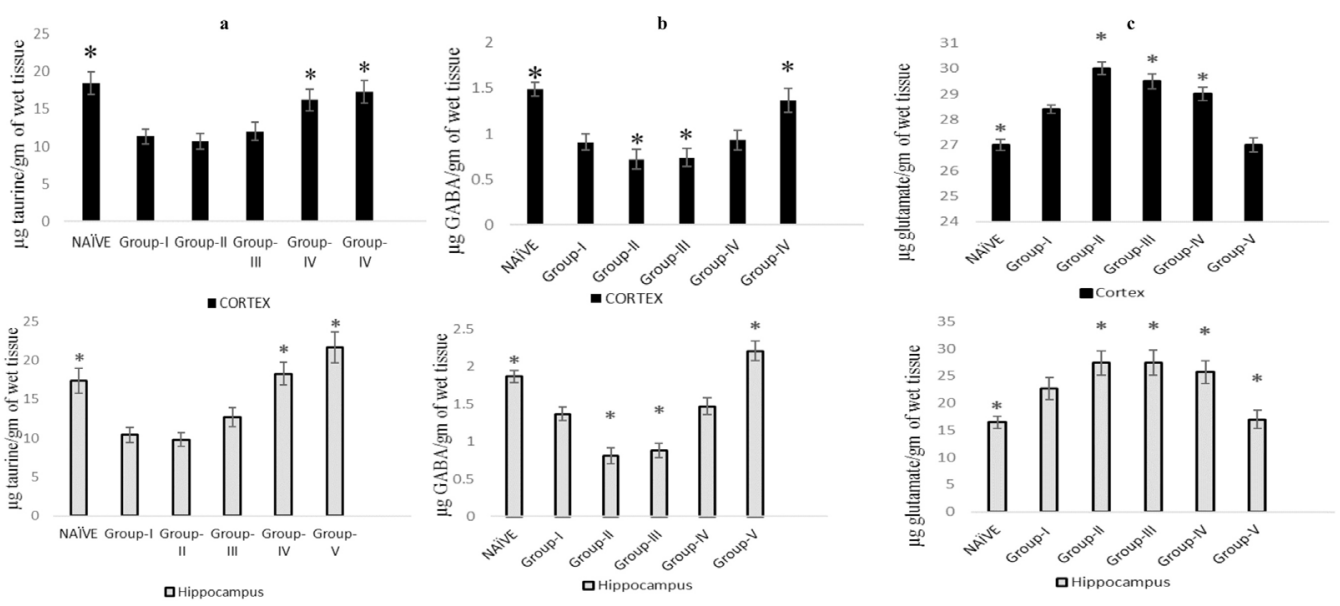

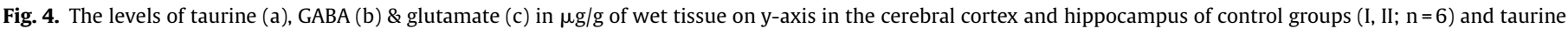

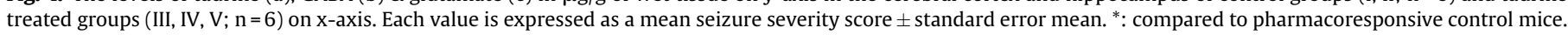

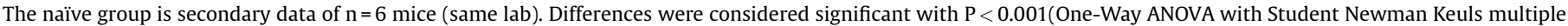
comparison post hoc).

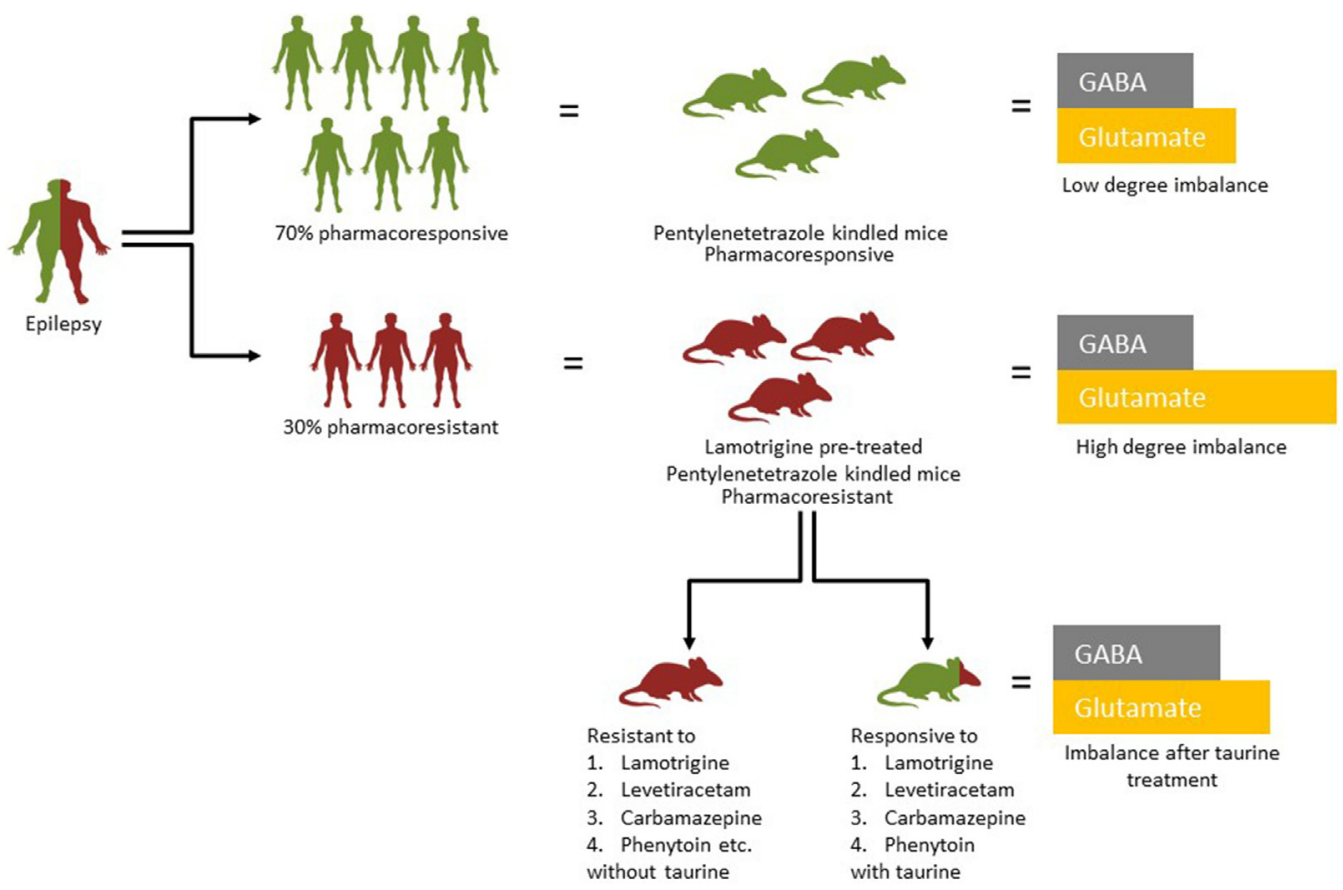

Fig. 5. Schematic illustration of the findings.

evident actions on pharmacoresponsive rodent seizures (ii) antiseizure effect of standard drugs after taurine supplementation (iii) and interplay between the levels of taurine and major excitatory \& inhibitory neurotransmitters i.e. GABA \& glutamate, in cerebral cortex and hippocampus regions of LPK mice (Fig. 5).

In similar to the anti-seizure effect of standard drugs (fig. 3 ) the taurine suppressed generalized tonic-clonic seizure on pentylenetetrazole-kindled animals that mimic core features of pharmacoresponsive epilepsy ${ }^{25}$ in line to the earlier reports suggesting its anti-seizure potential. ${ }^{22,23}$ It seems to be due to a direct agonistic action of taurine on $\mathrm{GABA}_{\mathrm{A}}$ receptors. ${ }^{18,19}$ However, seizure suppression was poor as compared to that of standard antiseizure drugs justifying their clinical preference over the taurine.

However, unlike to expected anti-seizure effect of taurine as clear from the large body of evidences ${ }^{22,23,38}$ and our observations with taurine on pentylenetetrazole-kindled animal in Fig. 3, significant $(\mathrm{P}<0.05)$ resistance to anti-seizure effect of taurine was observed on LPK mice that mimic core features of pharmacoresistant epilepsy. It suggests the possible inability of $\mathrm{GABA}_{\mathrm{A}}$ receptors mediated seizure suppression by taurine in LPK mice as well as the failure of standard anti-seizure drugs in the clinics.

In addition to the direct agonistic action of taurine on $\mathrm{GABA}_{\mathrm{A}}$, indirect potentiation in the GABAergic neurotransmission by taurine is well reported. ${ }^{20,21}$ Moreover, its wide margin of clinical safety further prompt us to use it as a supplement with available ASDs. Here, we found that anti-seizure actions of lamotrigine (15 mg/kg), levetiracetam (40 mg/kg), carbamazepine ( $40 \mathrm{mg} / \mathrm{kg})$ \& phenytoin $(35 \mathrm{mg} / \mathrm{kg})$ were significantly $(\mathrm{P}<0.05)$ improved after taurine supplementation with these drugs, at 100 and $200 \mathrm{mg} / \mathrm{Kg}$, i. p dose of taurine (Fig. 3).

It is likely that taurine mediated improvement in the antiseizure effect of tested standard drugs may be due to indirect 
potentiation of GABAergic neurotransmission, as evident that the taurine up-regulate GAD-positive neurons and as well as the activity of this key enzyme responsible for the conversion of excitatory neurotransmitter glutamate into inhibitory neurotransmitter GABA. ${ }^{20,21}$ Therefore, we estimated the levels of taurine, glutamate and GABA in cerebral cortex and hippocampus regions in mice brain.

According to results of this study, higher levels of taurine in the brain were strongly associated with significantly $(\mathrm{P}<0.05)$ upregulated GABA and down-regulated glutamate levels in taurine treated animals (Fig. 4) as compared to that of animals without taurine treatment. These neurochemical findings are favorable in justifying observed improvements in the anti-seizure effects of tested drugs after taurine supplementation, as one of the possible reason. Furthermore, significant lack of the anti-seizure effect of per se taurine reflects the true reversal of pharmacoresistance rather than additive effects of taurine and standard drugs.

Although, precise mechanism underlying poor anti-seizure response of standard drugs in LPK mice stay elusive, ${ }^{26-28}$ however in light of neurochemical findings of this study (Fig. 4) one testable hypothesis is that resistance is due to degree of imbalance between the inhibitory neurotransmitter GABA and excitatory neurotransmitter glutamate in LPK mice as compared to relatively lesser degree of imbalance in PK mice, and is further supported intrinsic severity hypothesis of pharmacoresistant epilepsy. ${ }^{40}$ Further studies need to explain secondary structural and functional changes associated with severity of this imbalance between excitatory and inhibitory neurotransmitters.

\section{Conflict of interest}

The authors have none to declare.

\section{Acknowledgments}

The authors would like to acknowledge the Council of Scientific and Industrial Research (CSIR) for the waters-chromatography system for neurochemical estimations vide No: 38(1339/12/EMRII) and Department of Pharmaceutical Science \& Drug Research, Punjabi University, Patiala (India) to provide infrastructures \& other facilities to carry out research work.

\section{References}

1. Brodie MJ. Pharmacological treatment of drug-resistant epilepsy in adults: a practical guide. Curr Neurol Neurosci Rep. 2016;16:82.

2. Jette N, Engel JJ. Refractory epilepsy is a life-threatening disease: lest we forget. Neurology. 2016;86:1932-1933.

3. Loscher W, Klitgaard H, Twyman RE, Schmidt D. New avenues for antiepileptic drug discovery and development. Nat Rev Drug Discov. 2013;12:757-776.

4. Engel JJ. What we do for people with drug-resistant epilepsy? The 2016 Wartenberg Lecture. Neurology. 2016;87:2483-2489.

5. Patsalos PN. Drug interactions with the newer antiepileptic drugs (AEDs) part1: pharmacokinetic and pharmacodynamic interactions between AEDs. Clin Pharmacokinet. 2013;52:927-966.

6. Berg AT. Comorbidities in epilepsies: overview. In: Panayiotopoulos CP, ed. Atlas of Epilepsies. London: Springer; 2010:1321-1324.

7. Benbadis SR. Non-pharmacological treatments for epilepsies: overview. In: Panayiotopoulos CP, ed. Atlas of Epilepsies. London: Springer; 2010:1621-1623.

8. Goodfellow M, Rummel C, Abela E, Richardson MP, Schindler K, Terry JR. Estimation of brain network ictogenicity predicts outcome from epilepsy surgery. Sci Rep. 2016;6:29215.

9. Gschwind M, Seeck M. Modern management of seizures and epilepsy. Swiss Med Wkly. 2016;146:w14310.
10. Jobst BC, Cascino GD. Resective epilepsy surgery for drug resistant focal epilepsy: a review. JAMA. 2015;313:285-293.

11. Bejarano E, Rodriguez-Navarro JA. Autophagy and amino acid metabolism in the brain: implications for epilepsy. Amino Acids. 2015:47:2113-2126.

12. Szyndler J, Turzynska D, Sobolewska A, et al. Changes in the concentration of amino acids in the hippocampus of pentylenetetrazole kindled rats. Neurosci Lett. 2008;439:245-249.

13. Van Gelder NM, Sherwin AL, Rasmussen T. Amino acids content of epileptogenic human brain: focal versus surrounding regions. Brain Res. 1972;40:385-393.

14. Clanton RM, Wu G, Akabani G, Aramavo R. Control of seizures by ketogenic diet-induced modulation of metabolic pathways. Amino Acids. 2017;49:1-20.

15. Ebrahimi HA, Ebrahimi S. Evaluation of charged amino acids on uncontrolled seizures. Neurol Res Int. 2015;2015:124507.

16. El ldrissi A, Trenkner E. Growth factors and taurine protect against excitotoxicity by stabilizing calcium homeostasis and energy metabolism. $J$ Neurosci. 1999;19:9459-9468.

17. Wu H, Jin Y, Wei J, Jin $\mathrm{H}$, Sha Wu JY. Mode of action of taurine as neuroprotector. Brain Res. 2005;1038:123-131.

18. Jia F, Yue M, Chandra D, et al. Taurine is a potent activator of extra synaptic GABA (A) receptors in the thalamus. J Neurosci. 2008;28:106-115.

19. Malminen O, Kontro P. Modulation of the GABA-benzodiazepine receptor complex by taurine in rat brain membranes. Neurochem Res. 1986;11:85-94.

20. L’Amoreaux WJ, Marsillo A, El-Idrissi A. Pharmacological characterization of GABAA receptors in taurine-fed mice. J Biomed Sci. 2010;17:14.

21. Levinskaya $\mathrm{N}$, Trenkner E, El ldrissi A. Increased GAD-positive neurons in the cortex of taurine fed mice. Adv Exp Med Biol. 2006;583:411-417.

22. Joseph MH, Emson PC. Taurine and cobalt induced epilepsy in the rat: a biochemical and electrocorticographic study. J Neurochem. 1976;27:14951501.

23. Lasley SM. Roles of neurotransmitter amino acids in seizure severity and experience in the genetically epilepsy prone rats. Brain Res. 1991;560:63-70.

24. Ghandforoush sattari M, Mashayekhi S, Krishna CV, Thompson JP, Rutledge PA. Pharmacokinetics of oral taurine in healthy volunteers. J Amino Acids. 2010;2010:346237.

25. Loscher W. The search for new screening models of pharmacoresistant epilepsy: is induction of acute seizure in epileptic rodents a suitable approach? Neurochem Res. 2016;42:1926-193810.1007/s11064-016-2025-7.

26. Singh E, Pillai KK, Mehndiratta M. Characterization of a lamotrigine resistant kindled model of epilepsy in mice: evaluation of drug resistance mechanism. Basic Clin Pharmacol Toxicol. 2014;115:373-378.

27. Srivastava AK, White HS. Carbamazepine but not valproate, displays pharmacoresistance in lamotrigine resistant amygdale kindled rats. Epilepsy Res. 2012;104:26-34.

28. Srivastava AK, Alex AB, Wilcox KS, White HS. Rapid loss of efficacy to the antiseizure drugs lamotrigine and carbamazepine: a novel experimental model of pharmacoresistant epilepsy. Epilepsia. 2013;54:1186-1194.

29. Mishra A, Goel RK. Psychoneurochemical investigations to reveal neurobiology of memory deficit in epilepsy. Neurochem Res. 2013;38:2503-2515.

30. Pahwa P, Goel RK. Ameliorative effect of Asparagus racemosus root extract against pentylenetetrazole induced kindling and associated depression and memory deficit. Epilepsy Behav. 2016;57:196-201.

31. Singh D, Mishra A, Goel RK. Effect of saponin fraction from Ficus religiosa on memory deficit, behavioural and biochemical impairments in pentylenetetrazole kindled mice. Epilepsy Behav. 2013;27:206-211.

32. Brodie MJ, Kwan P. Pharmacological properties of antiepileptic drugs and their significance in clinical practice. In: Panayiotopoulos CP, ed. Atlas of Epilepsies. London: Springer; 2010:1425-1430.

33. Löscher W. The pharmacokinetics of antiepileptic drugs in rats: consequences for maintaining effective drug levels during prolonged drug administration in rat models of epilepsy. Epilepsia. 2007;48:1245-1258.

34. Markowitz GJ, Kadam SD, Boothe DM, Irving ND, Comi AM. The pharmacokinetic of commonly used antiepileptic drugs in immature CD1 mice. Neuroreport. 2010;21:452-456.

35. Zapata A, Chefer VI, Shippensburg TS, Denoroy L. Detection and quantification of neurotransmitters in dialysates. Curr Protoc Neurosci. 2009;7:1-30.

36. Spijker S. Dissection of rodent brain regions. In: Li KW, ed. Neuroproteomics. Humana Press; 2011:13-26.

37. Gawande DY, Goel RK. Pharmacological validation of in-silico guided novel nootropic potential of Achyranthes aspera L. J Ethnopharmacol. 2015;175:324334.

38. Junyent F, Utrera J, Romero R, et al. Prevention of epilepsy by taurine treatments in mice experimental model. J Neurosci Res. 2009;87:1500-1508.

39. Li Z, Yamamoto Y, Morimoto T, Ono J, Okada S, Yamatodni A. The effect of pentylenetetrazole kindling on extracellular glutamate and taurine levels in the frontal cortex of rats. Neurosci. 2000;282:117-119.

40. Rogawski MA. The intrinsic severity hypothesis of pharmacoresistance to antiepileptic drugs. Epilepsia. 2013;54:33-40. 